\title{
Effect of bovine adenovirus 3 on mitochondria
}

\author{
Sanjeev K Anand ${ }^{1,2}$, Jaswant Singh ${ }^{3}$, Amit Gaba ${ }^{1,2}$ and Suresh K Tikoo ${ }^{1,2,4^{*}}$
}

\begin{abstract}
Viruses alter the structure and the function of mitochondria for survival. Electron microscopy analysis of the cells infected with bovine adenovirus 3 revealed extensive damage to the inner mitochondrial membrane characterized by dissolution of the cristae and amorphous appearance of mitochondrial matrix with little or no damage to the outer mitochondrial membrane. There were fewer cristae with altered morphology. Potential patches of protein synthesis machinary around mitochondria could be observed at 12 hours post infection (hpi). At 24 hpi, the multi vascular bodies were evident throughout the infected cell. ATP production, mitochondrial $\mathrm{Ca}^{2+}$ and mitochondrial membrane potential (MMP) peaked at $18 \mathrm{hpi}$ but decreased significantly at $24 \mathrm{hpi}$. This decrease coincided with the increased production of superoxide (SO) and reactive oxygen species (ROS), at 24 hpi indicating acute oxidative stress in the cells and suggesting a complete failure of the cellular homeostatic machinary. The results reveal an intericate relationship between $\mathrm{Ca}^{2+}$ homeostasis, the ATP generation ability of cells, SO and ROS production, and regulation of MMP following infection by bovine adenovirus 3 .
\end{abstract}

\section{Introduction}

Mitochondria are cytoplasmic organelles found in the eukaryotic cells. Their number and size varies from depending upon the function and the metabolic state of the cell. Although mitochondria have their own genome and transcription-translation machinery, they also depend on nuclear encoded gene products, which are indispensable for their normal function [1]. Besides acting as power houses of the cell, they are important for regulation of calcium and cellular metabolism [2] and play a central role in apoptosis [3]. Mitochondria have also been implicated in aging [3], development [4], antiviral responses [4] signal transduction [5] and diseases [6]. In short, they control the main processes critical for the survival of the cell. Thus, they have developed a very intimate and complex relationship with the cell, some of which is still elusive.

A number of viruses can affect the structure and the function of the mitochondria including oxidative stress, loss of mitochondrial membrane potential (MMP), and even depletion of the mitochondrial (mt) DNA [7].

Though adenovirus replicates in the nucleus of the cell, the possibility of its dependence on the mitochondria can't

\footnotetext{
* Correspondence: Suresh.tik@usask.ca

${ }^{1}$ Vaccine and Infectious Disease Organization -International Vaccine Center (VIDO- InterVac), University of Saskatchewan, Saskatoon, SK S7N 5E3, Canada ${ }^{2}$ Veterinary Microbiology, Western College of Veterinary Medicine, University of Saskatchewan, Saskatoon, SK S7N 5B4, Canada

Full list of author information is available at the end of the article
}

be ruled out. However, little is known about the role of mitochondria in adenovirus infections. Earlier reports reported the increase in the cellular respiration during release of adenovirus from the infected cells suggesting the role of mitochondria [8]. Some human adenovirus early proteins localize to the mitochondria and prevent apoptosis [9]. Adenovirus death protein (ADP) encoded by E3 region of human adenoviruses has been implicated in the release of virus progeny from the infected cell after successful replication.

Bovine adenovirus 3 (BAdV-3), a non-enveloped icosahedral particle of 75-nm diameter replicates in the respiratory tract of cattle with mild or no clinical symptoms [10]. The complete DNA sequence and the transcription map of BAdV-3 genome have been reported [11]. As little is known about BAdV-3-host interaction, the present study aims to identify the effect of BAdV-3 replication on the mitochondria of infected cells.

\section{Materials and methods \\ Cell culture}

Madin-Darby bovine kidney (MDBK) cells were grown in minimal essential medium (MEM; Invitrogen, Burlington, ON, Canada) supplemented with $10 \%$ heat-inactivated fetal bovine serum. Wild-type BAdV-3 (WBR-1 strain) was propagated in MDBK cells in MEM supplemented with 2\% FBS [12]. 


\section{Antibodies}

Production of polyclonal antibody specific to $19 \mathrm{kDa}$ E1B protein of BAdV-3 is described elsewhere [13]. Antibody specific to $42 \mathrm{kDa} \beta$-actin protein was purchased from Sigma, (Mississauga, ON, Canada) (Cat \# A5441). Alkaline phosphatase (AP)-conjugated goat anti-rabbit IgG (Cat \# 111-055-003) or AP-conjugated goat anti-mouse antibody (Cat \# 115-055-003) was purchased from Jackson ImmunoResearch, Philadelphia, USA.

\section{Western blot analysis}

Proteins from BAdV-3 infected cells were analyzed by Western blot as described earlier [12].

\section{Transmission electron microscopy}

The electron microscopy was performed as described earlier [12].

\section{Analysis of mitochondrial processes}

MDBK cells were grown in 96-well plates and infected with BAdV-3 at an MOI of 5 . At 0, 6, 12, 18 and $24 \mathrm{hpi}$, the infected or the uninfected cells were analyzed for cellular ATP production, levels of mitochondrial and cytosolic $\mathrm{Ca}^{2+}$, alteration in mitochondrial membrane potential, and production of mitochondrial reactive oxygen species (ROS) and Super oxide (S0) as described earlier [14].

\section{Statistical analysis}

Fluorescence data measured from "30000-40000" cells on an average and plotted as an average of 6 independent experiments for each function was collected and analyzed as described $[14,15]$.

\section{Computer programs}

All pictures have been generated using power point program included in Microsoft Office: Mac2011.

\section{Results}

\section{BAdV-3 damages mitochondrial architecture}

To evaluate the effect of BAdV-3 on mitochondria during the course of infection, electron microscopy was used. As seen in Figure 1A, the uninfected cells showed normal lamellar bodies with rough endoplasmic reticulum (rER) and many polyribosomes. Majority of the mitochondria were located in the peri-nuclear or central $2 / 3^{\text {rd }}$ of the cytoplasm. Mitochondria were elongated or oval in shape containing typical cristae of protein producing cells (panel a, b). At 6 hpi (panel c, d), mitochondria still appeared to have normal morphology with intact outer and the inner membranes. Although there were increased cristae free zones in the mitochondria, the density of the cristae appeared to be normal.

At 12 hpi (panel e, f), the mitochondria of the infected cells appeared to be smaller in size compared to the mitochondria of the normal cells (panel a, b). Although morphology was intact, the cristae free zones increased in the virus infected cell mitochondria at $12 \mathrm{hpi}$ compared to the infected cell mitochondria at 0 or 6 hpi. At 24 hpi (Figure 1B, panel a, b), the cells had longer microvilli on the surface and with fewer areas of a cell in contact with the other. The nuclear membrane was more indented with the appearance of nuclear inclusions. The progeny virus particles were observed inside the nucleus with the decrease in the number of nucleoli per cell. Moreover, the mitochondria appeared smaller and round/oval in shape. Interestingly, very few mitochondria were observed at this time and patches of the protein synthesis mahinary were not visible around the mitochondria.

\section{BAdV-3 regulates ATP production in infected cells}

Since BAdV-3 affects the mitochondrial morphology, we determined if ATP production capacity of the cells is compromised during the course of infection. ATP is present in all metabolically active cells and thus, is a marker for the cell viability. Whenever the cell is under stress, ATP concentration changes rapidly and thus, monitoring ATP is a good indicator of cell health. As seen in Figure 2, steady increase in ATP production was observed at 6,12 and 18 hpi. However, compared to $0,6,12$ and $18 \mathrm{~h}$, there was a significant $(P<0.0001)$ decrease in the ATP production at 24 hpi (Figure 2).

\section{BAdV-3 infection causes loss in mitochondrial membrane potential (MMP) in MDBK cells}

As changes were observed in mitochondrial morphology and ATP production in BAdV-3 infected cells, we next determined if BAdV-3 alters the MMP in the virusinfected cells (Figure 3). TMRM is a monovalent cationic mitochondrial selective probe, which exhibits fluorescence when it accumulates in MMP dependent manner. Under the conditions of the mitochondrial depolarization, TMRM diffuses out and becomes more evenly distributed throughout the cytoplasm. When dispersed, the fluorescence drops significantly, which can be quantified. Quantification of the TMRM signals indicated that there was a significant decrease (at $P<0.0001$ ) in the MMP in the cells from 0 to $6 \mathrm{hpi}$. In contrast, compared to 0 and $6 \mathrm{~h}$ there was a significant $(P<0.0001)$ increase in the MMP in the cells from 6 to 18 hpi. However, compared to $0,6,12$ and $18 \mathrm{~h}$, there was a significant $(P<0.0001)$ decrease in the MMP in the cells at 24 hpi.

\section{BAdV-3 infection causes decrease in mitochondrial $\mathrm{Ca}^{2+}$ levels in MDBK cells}

Since $\mathrm{Ca}^{2+}$ buffering capacity of the mitochondria is a good indicator of mitochondrial health and survival in the cells, the mitochondrial $\mathrm{Ca}^{2+}$ levels were measured after incubating BAdV-3 infected cells with Rhod-2 AM, 
Figure 1 Electron microscopy of BAdV-3 infected cells. (A) MDBK cells mock infected (panel a, b) or infected with wild-type BAdV-3 (panels c, d, e, f) at a MOI of 5 were analyzed after 6 (panel c, d) and 12 (panel e, f) hpi. Figures in the left panels (panels a, c, e) show the cytoplasm in the vicinity of the mitochondria. Area covered by white rectangles is enlarged and shown in the panels (panel $b, d, f$ ) on the right. Protein factories (PF) in the vicinity of the damaged mitochondria at 6 (panel d) and 12 (panel f) hpi. Bar $=0.25 \mu$. (B) MDBK cells infected with wild-type BAdV-3 at an $\mathrm{MOI}$ of 5 were analyzed at $24 \mathrm{hpi}$. An infected cell showing the virus particles $(V)$ in the nucleus and the damaged mitochondria $(M)$ in the cytoplasm (panel a). The enlarged area indicated by a rectangle (M) in panel "a" showing the mitochondria with amorphous internal structure in the cytoplasm of the infected cell (panel b). The enlarged area indicated by a rectangle $(V$ in panel "a" showing virus particles (indicated by arrows) in the nucleus of infected cells (panel c). Bar $=0.25 \mu$.

a high affinity mitochondrial $\mathrm{Ca}^{2+}$ indicator [16]. Rhod2 AM binds specifically with the mitochondrial $\mathrm{Ca}^{2+}$ and fluorescence can be quantified using a multi label reader. As seen in Figure 4A, the mitochondrial $\mathrm{Ca}^{2+}$ levels were found to be significantly higher at 6,12 and $18 \mathrm{~h}$ post BAdV-3 infection. However, compared to 0 , 6, 12 and $18 \mathrm{~h}$, there was a significant decrease in the mitochondrial $\mathrm{Ca}^{2+}$ levels from 18 hpi (Figure 4A). Similarly, cellular $\mathrm{Ca}^{2+}$ levels were measured by incubating BAdV-3 infected cells with Fluo-4 AM, a highly specific fluorescent dye for measuring the cytosolic $\mathrm{Ca}^{2+}$ levels in the cells [17]. Interestingly, there was no significant $(P<0.0001)$ change in the cytosolic $\mathrm{Ca}^{2+}$ levels of the infected cells from 0 to $12 \mathrm{hpi}$ (Figure 4B). In contrast, compared to 0,6 and $12 \mathrm{~h}$, there was significant $(P<$ $0.0001)$ increase in the cytosolic $\mathrm{Ca}^{2+}$ levels of the infected cells at 18 and $24 \mathrm{hpi}$ (Figure 4B).

\section{BAdV-3 infection aggravates the ROS \& superoxide production in MDBK cells}

To assess the respiratory function of the cells infected with BAdV-3, both reactive oxygen species (ROS) and SO production was measured. MitoSOX ${ }^{\mathrm{m}}$ Red reagent, a highly specific indicator of $\mathrm{SO}$, is specifically targeted to the mitochondria and fluoresces when oxidized by $\mathrm{SO}$ but not by other ROS or reactive nitrogen species (RNS) generating systems [18]. Similarly, DCF-DA is sensitive to all the other ROS except SO [19]. As seen in Figure 5A, compared to 0,6 and $12 \mathrm{~h}$, the increased levels of $\mathrm{SO}$ were observed at $18 \mathrm{hpi}$, which were significantly higher at 24 hpi. Similarly, compared to 0,6 and $12 \mathrm{~h}$, the increased levels of ROS were observed at $18 \mathrm{~h}$, which were significantly higher at $24 \mathrm{hpi}$ (Figure 5B).

\section{Discussion}

Mitochondria perform various functions that make them absolutely indispensable for the cell [3]. Besides acting as a powerhouse, they act as a common platform for the 

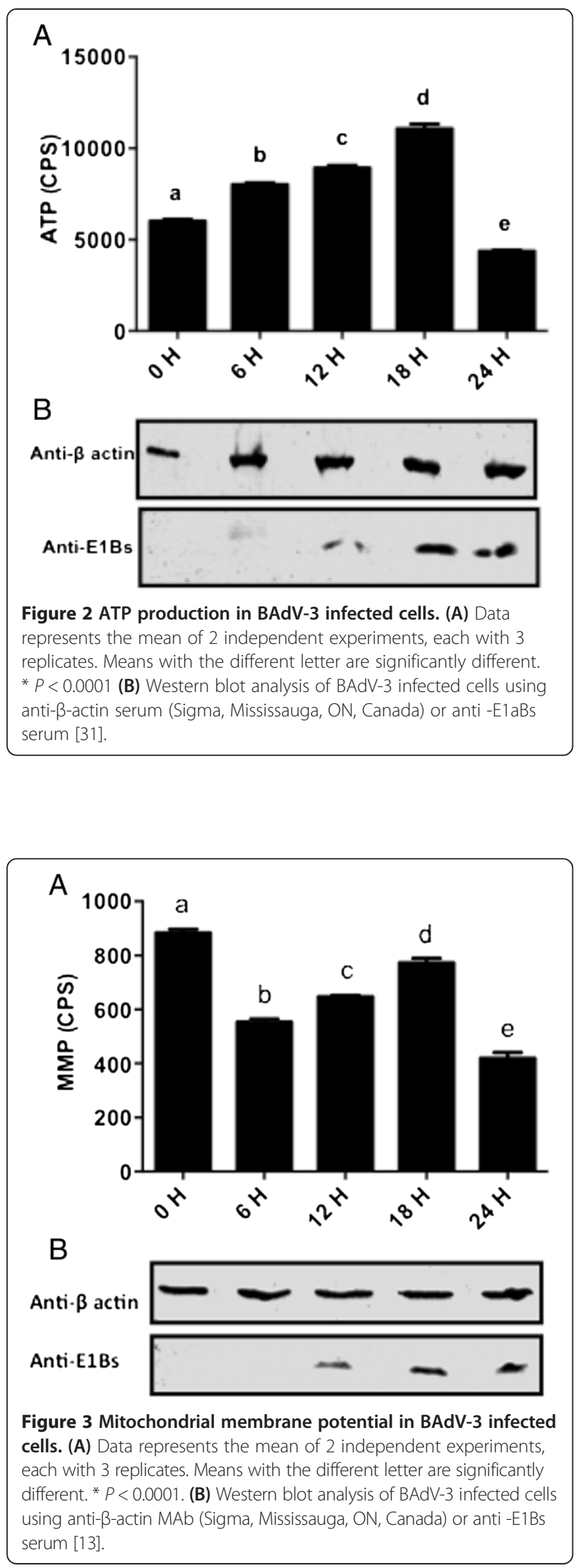

execution of a variety of cellular functions in the normal cells or in the cells under attack from the microorganisms including viruses [4]. A number of viruses affect the structure and the function of the mitochondria [7]. Here, we report the effects of BAdV-3 on the mitochondria during the normal course of infection of bovine cells.

Electron microscopy of BAdV-3 infected cells revealed extensive damage to the inner mitochondrial membrane characterized by the dissolution of cristae and amorphous appearance of the mitochondrial matrix while the outer mitochondrial membrane was observed to be intact. Various mitochondria specific lesions including degeneration of the mitochondria and dissolution of the mitochondrial cristae have been documented in Tobacco mosaic virus [20], Western Equine Encephalomyelitis (WEE) virus [21], vaccinia and fowl pox virus [22], and Echo virus type 9 [23] infected cells. Such changes in the mitochondria have been attributed to the dissipation of mitochondria membrane potential [24] due to opening of the membrane permeability transition pores [25]. Thus, invading viruses may be eliciting damage to the cristae by decreasing the synthesis or blocking the transport of the mitochondria specific proteins responsible for the maintenance of the inner mitochondrial membrane.

Different steps in viral replication including DNA packaging and capsid maturation require ATP [26]. Analysis of the ATP production during the course of BAdV-3 infection showed a steady increase in the ATP production till $18^{\text {th }} \mathrm{hpi}$, when the production of progeny virus particles is at its peak. As expected, the ATP levels decline after 18 hpi. This decline is in agreement with the culmination of the life cycle of BAdV-3. Variation in ATP production has also been associated with different stages of the viral life cycle indicating differential ATP requirements during the course of infection [27]. Increased level of ATP increases the viral replication including the release of vaccinia virus [28] and virus budding in influenza A virus [29] infected cells.

ATP is also required for the maintenance of most of the cellular and the mitochondrial functions [30]. Therefore, any change in cellular ATP production capacity will have direct impact on the membrane gradients inside the cell including the mitochondrial membrane potential (MMP). Our studies indicate that BAdV-3 modulates the MMP significantly at different times post infection. Initial transient decrease in MMP from 0-6 $\mathrm{h}$ followed by increase from 6-18 h may be due the expression of early adenoviral proteins. The role of adenovirus early proteins including E1A [31], E1B $19 \mathrm{~K}$ [32] and E4 orf4 [33] in the regulation of the longevity of the cell has been reported. A number of viruses including myxoma virus [34], hepatitis $\mathrm{C}$ virus (HCV) [35] and human immunedeficiency virus 1 (HIV-1) [36] modulate the MMP for their benefit by 


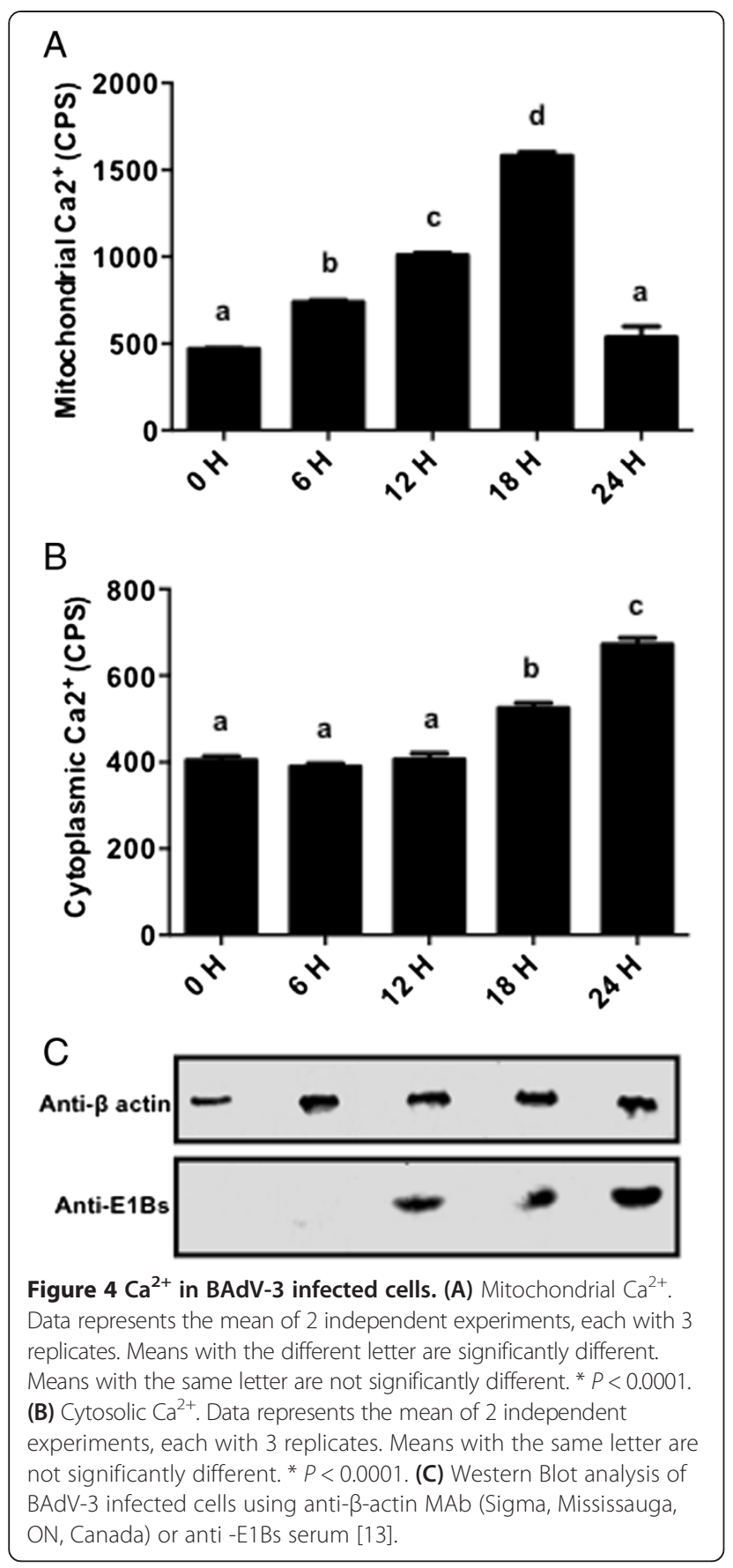

altering the activity of one or more components viz., the permeability transition pore (PTP) [37], the voltage dependent anionic channels (VDACs) [38] and the membranes. As expected, at $24 \mathrm{hpi}$, the MMP showed significant decrease, which coincides with the observed damage to the mitochondria and decreased ATP levels. Thus, increased ATP levels and prevention of the loss of MMP results in the prevention of the cell death, which is beneficial for the replication of BAdV-3. It is tempting to speculate that one or more BAdV-3 protein (s) may be involved in
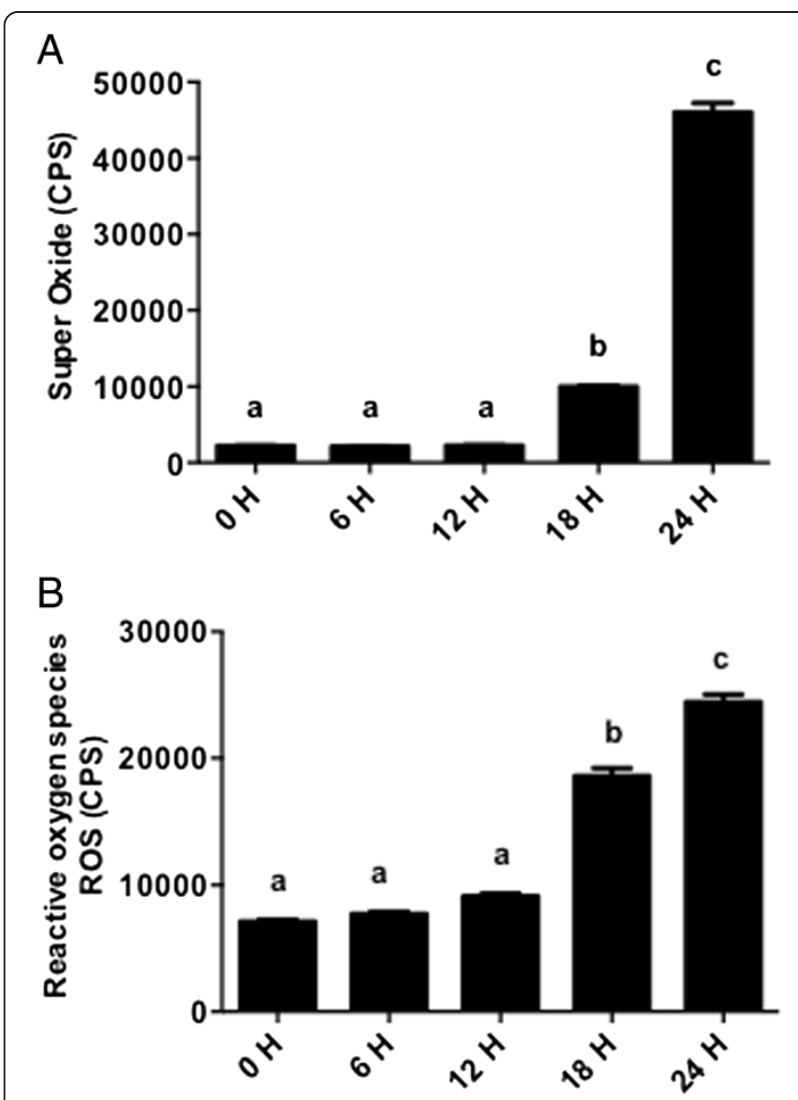

C

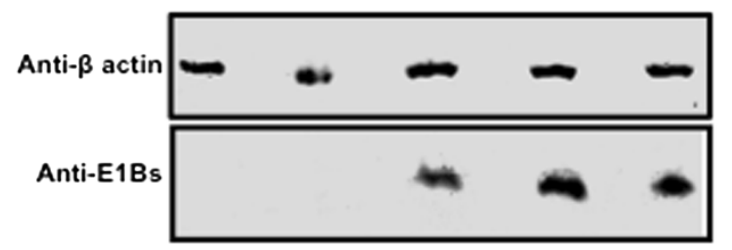

Figure $\mathbf{5}$ Induction of Superoxide (SO) and reactive oxygen species (ROS) in BAdV-3 infected cells. (A) SO production. Data represents the mean of 2 independent experiments, each with 3 replicates. Means with the same letter are not significantly different. ${ }^{*} P<0.0001$. (B) ROS production. Data represents the mean of 2 independent experiments, each with 3 replicates. Means with the different letter are significantly different. Means with the same letter are not significantly different. ${ }^{*} P<0.0001$. (C) Western blot of BAdV-3 infected cells using anti- $\beta$-actin MAb (Sigma, Mississauga, ON, Canada) or anti -E1Bs serum [13].

interactions with the mitochondria to help in increasing the ATP levels and the MMP. Recently, we reported that BAdV-3 pVII protein increases the ATP levels and maintain the MMP in transfected cells [14].

$\mathrm{Ca}^{2+}$ is one of the most abundant and most universal signal carriers which acts as a second messenger to regulate many cellular processes [39] including the ATP synthesis [40] and maintenance of the MMP [41]. The ATP levels [40] and the MMP regulate the $\mathrm{Ca}^{2+}$ homeostasis in the cells [42] and vice versa indicating a complex relationship 
between them. Our study didn't show a significant shift in cytosolic $\mathrm{Ca}^{2+}$ levels. In contrast, the mitochondrial $\mathrm{Ca}^{2+}$ was observed to have peak retention at $18 \mathrm{hpi}$, similar to what we observed for the ATP and the MMP. We believe that BAdV-3 causes the retention of $\mathrm{Ca}^{2+}$ in the mitochondria, which leads to increase in the ATP synthesis, thus helping in the maintenance of the MMP. In addition to mitochondria, ER acts as a major source of $\mathrm{Ca}^{2+}$ in the cell. It is possible that whatever is the $\mathrm{Ca}^{2+}$, mitochondria uptake and retain during the process, ER releases the equivalent to make it up so that the cytosolic $\mathrm{Ca}^{2+}$ concentration remains the same. Thus, increase in the mitochondrial $\mathrm{Ca}^{2+}$ leads to increase in the ATP, the MMP and decrease in the ROS, which in turn may alter the apoptotic signalling [43]. Alterations in the mitochondrial $\mathrm{Ca}^{2+}$ levels [44] have been reported during $\mathrm{HCV}$ or herpes simplex virus 1 (HSV-1) [45] infection.

A variety of cellular defence mechanisms and enzymes including superoxide dismutase, catalases, lacto peroxidases, glutathione peroxidases and peroxiredoxins maintain the steady state concentration of the cellular oxidants at non-toxic levels [46]. This delicate balance between oxidant generation and metabolism may be disrupted by various xenobiotics including the viral proteins. This imbalance between the oxidant (e.g. ROS, SO) production and the antioxidant cellular defences cause the cell death. As expected, the oxidative stress could be observed in the later phases of BAdV-3 infection, which may be the primary factor leading to the death of the infected cells. A number of viruses including human adenovirus 5 (HAdV-5) cause oxidative stress in the cells [47-49] which has been associated with the release of progeny virus [50].

Stimulus for the mitochondria to perform beyond their usual capacity comes from various factors including stress caused to the cell by ROS. It is known that the oxidative stress causes an increase in mt DNA copy number and stimulates the nucleus to synthesize the proteins required for the mitochondrial biogenesis [51]. This scenario plays two roles in the affected cells. During initial stages (6-12 hpi) of BAdV-3 infection, when the cells are relatively healthy, they have higher antioxidant capacity and good quality of mitochondrial DNA. So, the mild oxidative stress during this phase of infection may be causing an increase in the mitochondrial DNA leading to the proliferation of mitochondria with healthy cristae. This increases the total surface area available for ATP synthesis (cristae), which in turn compensates for the increased energy supply of the cell under given conditions. Such activity has also been loosely implicated to prevent the apoptosis in human cytomegalovirus (HCMV) infected cells [52].

These mitochondria will be able to cause increase in ATP synthesis, supply energy and participate in anti-apoptotic activities. Moreover, not all the cristae are damaged during the initial phases of infection and the remaining cristae may be producing ATP at increased levels along with healthy mitochondria produced as a result of biogenesis, which explains the increase in ATP production when some of the crisate are observed to be damaged. At $18 \mathrm{hpi}$, when the oxidative stress has started to rise but it is still below threshold to produce faulty $\mathrm{mt}$ DNA and thus faulty mitochondria. At this time it is possible that there are some proportion of faulty mitochondria generating ROS. When ROS threshold is crossed, the cell falls into ROS loop inflicting further damage to the mitochondria (as seen in $24 \mathrm{~h}$ ) and dies releasing the progeny virus.

Complete loss of the internal architecture of mitochondria at $24 \mathrm{hpi}$ indicated that the organelle was one of the main targets of the BAdV-3 during infection. The functional analysis revealed that the functions of the mitochondria were not compromised till late during the infection. This is consistent with the fact that the completion of virus cycle requires supply of ATP. Interestingly, at late times post infection, the mitochondria were located near the protein factories (possibly virus factories). Taken together, these results suggested that the mitochondria are active till late times post infection, when they lose the internal architecture consistent with providing energy required for the release of the virus. These observations allow us to speculate that virus takes the vital mitochondrial processes under its control early during the infection and abandons the organelle once the life cycle is over.

In conclusion, our study demonstrated that there is a delicate balance between the cellular functions, the mitochondrial physiology and BAdV-3 replication. Moreover, during early stages of BAdV-3 infection, the retention of $\mathrm{Ca}^{2+}$ by mitochondria may prevent the loss of MMP and, decrease the SO and the ROS production by the infected cells, prolonging the cell survival for efficient production of the progeny BAdV-3 virions.

\section{Competing interests}

The authors declare that they have no competing interests.

\section{Authors' contributions}

SKA was responsible for lab work, data analysis and writing of the first draft of the manuscript. JS provided expertise for EM and helped with the interpretation of the EM data. AG participated in electron microscopy studies involving preparation of samples and interpretation of the results. SKT conceived the project, designed experimental approach and writing of the manuscript. All authors read and approved the final version.

\section{Acknowledgements}

Authors are thankful to other members of "Tikoo Laboratory" for helpful suggestions, Electron microscopy unit at WCVM veterinary College. Published as VIDO article \# 698. AG was supported by enhancement fund of WCVM,

University of Saskatchewan and Bigland Fellowship, VIDO-InterVac, University of Saskatchewan. The work was supported by a discovery grant from Natural Sciences and Engineering Research Council of Canada to SKT. 


\section{Author details}

${ }^{1} V a c c i n e$ and Infectious Disease Organization -International Vaccine Center (VIDO- InterVac), University of Saskatchewan, Saskatoon, SK S7N 5E3, Canada. ${ }^{2}$ Veterinary Microbiology, Western College of Veterinary Medicine, University of Saskatchewan, Saskatoon, SK S7N 5B4, Canada. ${ }^{3}$ Veterinary Biomedical Sciences, Western College of Veterinary Medicine, University of Saskatchewan, Saskatoon, SK S7N 5B4, Canada. ${ }^{4}$ Vaccinology \& Immunotherapeutics program, School of Public Health, University of Saskatchewan, Saskatoon, SK S7N 5E5, Canada.

Received: 6 December 2013 Accepted: 31 March 2014 Published: 16 April 2014

\section{References}

1. Rapaport D: Finding the right organelle. Targeting signals in mitochondrial outer-membrane proteins. EMBO Rep 2003, 4:948-952.

2. Hackenbrock CR: Ultrastructural bases for metabolically linked mechanical activity in mitochondria. I. Reversible ultrastructural changes with change in metabolic steady state in isolated liver mitochondria. J Cell Biol 1966, 30:269-297.

3. Chan DC: Mitochondria: dynamic organelles in disease, aging, and development. Cell 2006, 125:1241-1252.

4. Seth RB, Sun L, Chen ZJ: Antiviral innate immunity pathways. Cell Res 2006, 16:141-147.

5. Bossy-Wetzel E, Barsoum MJ, Godzik A, Schwarzenbacher R, Lipton SA: Mitochondrial fission in apoptosis, neurodegeneration and aging. Curr Opin Cell Biol 2003, 15:706-716.

6. McFarland R, Taylor RW, Turnbull DM: Mitochondrial disease-its impact, etiology, and pathology. Curr Topics Dev Biol 2007, 77:113-155.

7. Anand SK, Tikoo SK: Viruses as modulators of mitochondrial functions. Adv Virol 2013, 2013:738794

8. Tollefson AE, Ryerse JS, Scaria A, Hermiston TW, Wold WS: The E3-11.6-kDa adenovirus death protein (ADP) is required for efficient cell death: characterization of cells infected with adp mutants. Virology 1996, 220:152-162.

9. Lomonosova E, Subramanian T, Chinnadurai G: Mitochondrial localization of p53 during adenovirus infection and regulation of its activity by E1B-19 K. Oncogene 2005, 24:6796-6808.

10. Thompson KG, Thomson GW, Henry JN: Alimentary tract manifestations of bovine adenovirus infections. Can Vet J 1981, 22:68-71.

11. Reddy PS, Idamakanti N, Zakhartchouk AN, Baxi MK, Lee JB, Pyne C, Babiuk LA, Tikoo SK: Nucleotide sequence, genome organization, and transcription map of bovine adenovirus type 3. J Virol 1998, 72:1394-1402.

12. Kulshreshtha $V$, Babiuk LA, Tikoo SK: Role of bovine adenovirus-3 $33 \mathrm{~K}$ protein in viral infection. Virology 2004, 323:59-69.

13. Reddy PS, Chen Y, Idamakanti N, Pyne C, Babiuk LA, Tikoo SK: Characterization of early region 1 and $\mathrm{pIX}$ of bovine adenovirus-3. Virology 1999, 253:299-308.

14. Anand SK, Gaba A, Singh J, Tikoo SK: Bovine adenovirus 3 core protein pVII localise to mitochondria and modulate ATP synthesis, mitochondrial CA2+ and mitochondrial membrane potential. J Gen Virol 2014, 95:442-452.

15. Anscombe FJ: The validity of comparative experiments. $J$ R Stat Soc Ser A $1948,111: 181-211$

16. Mothet JP, Fossier P, Meunier FM, Stinnakre J, Tauc L, Baux G: Cyclic ADP-ribose and calcium-induced calcium release regulate neurotransmitter release at a cholinergic synapse of Aplysia. J Physiol 1998, 507:405-414.

17. Gee KR, Brown KA, Chen WN, Bishop-Stewart J, Gray D, Johnson I: Chemical and physiological characterization of fluo-4 Ca (2+)-indicator dyes. Cell Calcium 2000, 27:97-106

18. Mukhopadhyay P, Rajesh M, Yoshihiro K, Hasko G, Pacher P: Simple quantitative detection of mitochondrial superoxide production in live cells. Biochem Biophys Res Commun 2007, 358:203-208.

19. Degli-Esposti M: Measuring mitochondrial reactive oxygen species. Methods 2002, 26:335-340

20. Weintraub M, Ragetli HW: An Electron microscope study of tobacco mosaic virus lesions in njotiana glutinosa L. J Cell Biol 1964، 23:499-509.

21. Morgan C, Howe C, Rose HM: Structure and development of viruses as observed in the electron microscope. V. Western equine encephalomyelitis virus. J Exp Med 1961, 113:219-234.
22. Morgan C, Ellison SA, Rose HM, Moore DH: Structure and development of viruses observed in the electron microscope. II. Vaccinia and fowl pox viruses. J Exp Med 1954, 100:301-310

23. Rifkind RA, Godman GC, Howe C, Morgan C, Rose HM: Structure and development of viruses as observed in the electron microscope. VI. ECHO virus, type 9. J Exp Med 1961, 114:1-12

24. Jaeschke H, Gores GJ, Cederbaum Al, Hinson JA, Pessayre D, Lemasters JJ: Mechanisms of hepatotoxicity. Toxicol Sci 2002, 65:166-176.

25. Pessayre D, Mansouri A, Haouzi D, Fromenty B: Hepatotoxicity due to mitochondrial dysfunction. Cell Biol Toxicol 1999, 15:367-373.

26. Tien CF, Cheng FC, Ho YP, Chen YS, Hsu JH, Chang RY: Inhibition of aldolase A blocks biogenesis of ATP and attenuates Japanese encephalitis virus production. Biochem Biophys Res Commun 2014, 443:464-469.

27. Klumpp K, Ford MJ, Ruigrok RW: Variation in ATP requirement during influenza virus transcription. J Gen Virol 1998, 79:1033-1045.

28. Chang CW, Li HC, Hsu CF, Chang CY, Lo SY: Increased ATP generation in the host cell is required for efficient vaccinia virus production. J Biomed Sci 2009, 16:80.

29. Hui EK, Nayak DP: Role of ATP in influenza virus budding. Virology 2001, 290(2):329-341.

30. Hardie DG, Scott JW, Pan DA, Hudson ER: Management of cellular energy by the AMP-activated protein kinase system. FEBS Lett 2003, 546:113-120.

31. White E: Regulation of the cell cycle and apoptosis by the oncogenes of adenovirus. Oncogene 2001, 20:7836-7846.

32. Degenhardt K, Perez D, White E: Pathways used by adenovirus E1B $19 \mathrm{~K}$ to inhibit apoptosis. Symp Soc Exp Biol 2000, 52:241-251.

33. Kleinberger $\mathrm{T}$ : Induction of apoptosis by adenovirus E4orf4 protein. Apoptosis 2000, 5:211-215.

34. Everett H, Barry M, Lee SF, Sun X, Graham K, Stone J, Bleackley RC, McFadden G: M11L: a novel mitochondria-localized protein of myxoma virus that blocks apoptosis of infected leukocytes. J Exp Med 2000, 191:1487-1498.

35. Machida K, Cheng KT, Lai CK, Jeng KS, Sung VM, Lai MM: Hepatitis C virus triggers mitochondrial permeability transition with production of reactive oxygen species, leading to DNA damage and STAT3 activation. J Virol 2006, 80:7199-7207.

36. Deniaud A, Brenner C, Kroemer G: Mitochondrial membrane permeabilization by HIV-1 Vpr. Mitochondrion 2004, 4:223-233.

37. Bernardi P: Mitochondrial transport of cations: channels, exchangers, and permeability transition. Physiol Rev 1999, 79:1127-1155.

38. Colombini M, Blachly-Dyson E, Forte M: VDAC, a channel in the outer mitochondrial membrane. Ion Channels 1996, 4:169-202

39. Berridge MJ, Bootman MD, Lipp P: Calcium-a life and death signal. Nature 1998, 395:645-648.

40. Balaban RS: The role of $\mathrm{Ca}(2+)$ signaling in the coordination of mitochondrial ATP production with cardiac work. Biochim Biophys Acto 2009, 1787:1334-1341

41. Liu Y, Gao L, Xue Q, Li Z, Wang L, Chen R, Liu M, Wen Y, Guan M, Li Y, Wang S: Voltage-dependent anion channel involved in the mitochondrial calcium cycle of cell lines carrying the mitochondrial DNA A4263G mutation. Biochem Biophys Res Commun 2011, 404:364-369.

42. Agudo-Lopez A, Miguel BG, Fernandez I, Martinez AM: Role of protein kinase $C$ and mitochondrial permeability transition pore in the neuroprotective effect of ceramide in ischemia-induced cell death. FEBS Lett 2011, 585:99-103.

43. Pinton P, Ferrari D, Rapizzi E, Di Virgilio F, Pozzan T, Rizzuto R: The Ca2+ concentration of the endoplasmic reticulum is a key determinant of ceramide-induced apoptosis: significance for the molecular mechanism of $\mathrm{Bcl}-2$ action. EMBO J 2001, 20:2690-2701.

44. Piccoli C, Scrima R, D’Aprile A, Ripoli M, Lecce L, Boffoli D, Capitanio N: Mitochondrial dysfunction in hepatitis $\mathrm{C}$ virus infection. Biochim Biophys Acta 2006, 1757:1429-1437.

45. Lund K, Ziola B: Cell sonicates used in the analysis of how measles and herpes simplex type 1 virus infections influence Vero cell mitochondrial calcium uptake. Can J Biochem Cell Biol 1985, 63:1194-1197.

46. Brkic S, Maric D, Tomic S, Dimitrijevic R: Viral infections and oxidative stress. Vojnosanit Pregl 2010, 67:1015-1020 (in Serbian).

47. McGuire KA, Barlan AU, Griffin TM, Wiethoff CM: Adenovirus type 5 rupture of lysosomes leads to cathepsin B dependent mitochondrial stress and production of reactive oxygen species. J Virol 2011, 85:10806-10813. 
48. Baum MK, Sales S, Jayaweera DT, Lai S, Bradwin G, Rafie C, Page JB, Campa A: Coinfection with hepatitis $C$ virus, oxidative stress and antioxidant status in HIV-positive drug users in Miami. HIV Med 2011, 12:78-86.

49. Ming-Ju H, Yih-Shou H, Tzy-Yen C, Hui-Ling C: Hepatitis C virus E2 protein induce reactive oxygen species (ROS)-related fibrogenesis in the HSC-T6 hepatic stellate cell line. J Cell Biochem 2011, 112:233-243.

50. Arimoto E, Iwai S, Sumi T, Ogawa Y, Yura Y: Involvement of intracellular free $\mathrm{Ca} 2+$ in enhanced release of herpes simplex virus by hydrogen peroxide. Virol J 2006, 3:62.

51. Lee $\mathrm{HC}$, Yin PH, Lu CY, Chi CW, Wei YH: Increase of mitochondria and mitochondrial DNA in response to oxidative stress in human cells. Biochem J 2000, 348:425-432.

52. McCormick AL, Smith VL, Chow D, Mocarski ES: Disruption of mitochondrial networks by the human cytomegalovirus UL37 gene product viral mitochondrion-localized inhibitor of apoptosis. J Virol 2003, 77:631-641.

doi:10.1186/1297-9716-45-45

Cite this article as: Anand et al:: Effect of bovine adenovirus 3 on mitochondria. Veterinary Research 2014 45:45.

\section{Submit your next manuscript to BioMed Central and take full advantage of:}

- Convenient online submission

- Thorough peer review

- No space constraints or color figure charges

- Immediate publication on acceptance

- Inclusion in PubMed, CAS, Scopus and Google Scholar

- Research which is freely available for redistribution 